\title{
Wheezing in infants: can we separate the wheat from the chaff?
}

Wheezing in the first years of life has a high prevalence worldwide and poses a major challenge. The management of wheezing is usually frustrating both for physicians and parents, who see the gradual increase in the therapeutic armamentarium that keeps adding to their children's "preventive" treatment, usually with no changes perceived in episode frequency or severity. It should be noted that the term "preventive treatment" is not present in the international literature, where we will only find references to asthma "control treatment".

Different studies have shown that wheezing occurs in up to $50 \%$ of children younger than 3 years old, and the most common cause of wheezing are respiratory infections, mainly of viral etiology. These children usually have risk factors for recurrent respiratory infections, such as having school age siblings or attending a daycare center, among other factors. However, many times nasopharyngeal secretion tests by indirect immunofluorescence are negative, thus the viral etiology is ruled out. The use of molecular techniques in Argentina has helped to identify the viral etiology of infections in over $60 \%$ of children seen as outpatients and in over $80 \%$ of hospitalized children with compatible symptoms. ${ }^{1}$

In spite of the reasons already mentioned and clearly known by pediatricians, recurrent wheezing in infants results in a growing and indiscriminate use of steroidal anti-inflammatory drugs. Several studies have shown that low doses of inhaled corticosteroids have no impact on the development of the hypothalamic-pituitaryadrenal axis in these children; however, other studies have demonstrated that higher doses do have an effect on this axis, in addition to the fact that their younger age or lower weight significantly increase the adverse event rate. One study on the growth of infants and toddlers two years after discontinuation of inhaled fluticasone $100 \mathrm{mcg}$ twice daily versus placebo found that those receiving the drug had grown $1.6 \mathrm{~cm}$ less compared to baseline values in 2 year old children with a weight of less than $17 \mathrm{~kg}$. ${ }^{2}$

More than 10 years ago, Castro Rodríguez published the Asthma Predictive Index (API) using the Tucson cohort children; this index was based on major and minor criteria. One criterion of particular interest is the presence of wheezing not associated with colds, which is the most common cause of wheezing in infants and toddlers, and of inadequate treatments, as already mentioned. In all publications making a reference to the API, Castro Rodríguez focuses on its strength to demonstrate which children will not present asthma (high negative predictive value), but points out that it is not strong enough as a predictor for those who will develop asthma. He was also part of a group that reproduced the index in Colombia and found much lower sensitivity and specificity values than those previously described. ${ }^{3}$

For this reason it is necessary to have supportive methods to improve these indexes' sensitivity or, in other words, find out who out of these infants and toddlers could actually develop asthma at school age and benefit from an anti-inflammatory treatment that will prevent the early narrowing of airways. It would also be important to be able to detect who of these infants and toddlers would actually benefit from an anti-inflammatory treatment, even if they do not develop asthma at a later stage, in order to reduce the indiscriminate use of these drugs. The prevention of early asthma in kids (PEAK) trial has shown that children with a positive API who received daily treatment with fluticasone had a significant clinical improvement versus those who received placebo. ${ }^{4}$ This study had two limitations: it was conducted in children with a mean age of $3 \pm 0.6$ years old, and children with a negative API had been excluded.

In this issue of the Archivos Argentinos de Pediatría, Balinotti, et al. evaluated the association between the API and the fraction of exhaled nitric oxide $\left(\mathrm{FE}_{\mathrm{NO}}\right)$ (see page 191). ${ }^{5}$ There is a clear correlation between this marker and the degree of eosinophilic airway inflammation, and it is known that patients with this kind of inflammation have a better response to anti-inflammatory treatment, especially to inhaled corticosteroids. Several studies have shown that children with recurrent wheezing and low $\mathrm{FE}_{\mathrm{NO}}$ levels may have a better response to leukotriene receptor antagonists than to inhaled corticosteroids. ${ }^{6}$

As with the introduction of pulmonary function tests in infants, this group is once more using a novel technique in the country, which consists of detecting levels of exhaled nitric oxide in very small infants during tidal breathing while the child is asleep or in a calm, awake state. It is worth mentioning that these patients are signi- 
ficantly younger than those participating in the PEAK trial, and that they strictly follow the API criteria. The sample was not large, but results are significant and valuable.

More studies are clearly needed, and this technique is still experimental and still not ready to be used in the treatment of patients, but I completely agree with the conclusion drawn by Dr. Balinotti, et al. that the determination of $\mathrm{FE}_{\mathrm{NO}}$ levels can help identify subgroups of children with similar respiratory symptoms but different progress and therapeutic responses.

Santiago M. Vidaurreta, M.D. Pediatric Neumonologist Head of the Department of Pediatrics. Hospital Universitario CEMIC.

http:/ /dx.doi.org/10.5546/aap.2013.188
1. Marcone DN, Ellis A, Videla C, et al. Viral Etiology of Acute Respiratory Infections in Hospitalized and Outpatient Children in Buenos Aires, Argentina. Pediatric Infectious Disease Journal 32(3):e105-e110, March 2013.

2. Guilbert, T.W.; Mauger, D.T.; Allen, D.B.; Zeiger, R.S.; et al. Growth of preschool children at high risk for asthma 2 years after discontinuation of fluticasone. J Allergy Clin Immunol 2011;128: 956-63.

3. Rodriguez-Martinez CE, Sossa-Briceno MP, Castro-Rodriguez JA. Discriminative properties of two predictive indices for asthma diagnosis in a sample of preschoolers with recurrent wheezing. Pediatr Pulmonol 2011;46:1175-81.

4. Theresa W. Guilbert,., Wayne J. Morgan,., Robert S. Zeiger, M.D. et al. Long-Term Inhaled Corticosteroids in Preschool Children at High Risk for Asthma. N Engl J Med May 11, 2006; 354:1985-1997.

5. Dr. Juan Emilio Balinotti, Dr. Alejandro Colom, Dr. Carlos Kofman y Dr. Alejandro Teper. Asociación entre el índice de predicción de asma y el óxido nítrico exhalado en niños pequeños con sibilancias recurrentes. Arch Argent Pediatr 2013;111(2):000-000/1

6. Nathan Rabinovitch, Nora J. Graber, Vernon M. Chinchilli, et al. Urinary leukotriene E4/exhaled nitric oxide ratio and montelukast response in childhood asthma. J Allergy Clin Immunol 2010;126:545-51.

\section{Asessment of infants with respiratory distress}

Acute lower respiratory tract infections (ALRTIs) represent a heavy burden on health systems each winter when they are faced with providing care to thousands of affected children.

The burden of disease was estimated at 94037000 "DALYs" (disability-adjusted life years) and 3900000 deaths in $2001 .{ }^{1}$ The implementation of healthcare programs based on simple components that allow to classify patients according to the seriousness of their condition and, from this, to follow standardized measures can be an effective response to this situation.

Respiratory distress is related to the severity of the clinical condition, and such severity may lead to a cardiorespiratory dysfunction and death. In the case of infants with ALRTI, one of the top priorities is to maintain adequate levels of blood oxygen, so that hypoxemia can be avoided and treated on a timely manner.

In scenarios when it is not possible to measure oxygen saturation $\left(\mathrm{O}_{2}\right.$ sat), it is very important to assess respiratory distress using scores based on simple clinical elements (respiratory rate, wheezing, cyanosis, heart rate, intercostal retraction, etc.).

It is not easy to establish when or where this practice was first implemented. It is quite likely that the Silverman-Andersen score was one of the first approaches to standardize the assessment of respiratory distress syndrome. ${ }^{2}$ It is of little importance if it started in a study aimed at assessing the impact of the use of "mist" on the mortality of premature newborn infants. Its publication in textbooks of pediatrics led to a rapid dissemination of the score. Moreover, a decade later Dabbous ${ }^{3}$ included the SilvermanAndersen score in his "Bronchiolitis Score", a complex assessment scheme of respiratory distress (made up of 9 components) designed to evaluate the effect of corticosteroids on the treatment of bronchiolitis; thus, this practice was extended to be used in infants up to 18 months old.

In 1974 Pierson, Bierman, and Kelley simplified the "Bronchiolitis Score" 4 by developing what they called the "Pulmonary Index." This scoring system was initially developed to assess the response to corticosteroid therapy in children aged 5 to 18 years old with status asthmaticus, but it has been more commonly used given its simplicity. In 1983, Tal, et al. ${ }^{5}$ used the Pulmonary Index to assess the efficacy of salbutamol and dexamethasone in infants with wheezing, and in order to make patients assessment even easier, they decided to modify one of the elements of the score developed by Pierson, et al.: ${ }^{4}$ they replaced 
the inspiratory-expiratory ratio by the presence of cyanosis.

Soon after, Lowell, et al. designed an even simpler tool to objectively evaluate the response of wheezing infants to adrenalin: the Respiratory Distress Assessment Instrument (RDAI). ${ }^{6}$ This scale only considers wheezing and chest retractions and it has become a widely used tool in the Northern Hemisphere.

All these instruments were initially developed to assess treatment effectiveness in pilot studies, not to be used in daily practice to decide on the approach of patients with respiratory distress syndrome. Probably because of this, it had not been expected that the score developed by Tal, et al. ${ }^{5}$ would have had such a wide dissemination in South America with its inclusion in the program implemented by Chile to face the high infant mortality rates due to ALRTIs. It is likely that the fact of being cited in a well-known textbook of pediatrics has probably resulted in other countries also including this score in their ALRTI programs. ${ }^{7}$ It should be noted that Tal's score was also subject to adaptations and amendments. In this context, Chile ${ }^{8}$ and $\mathrm{Peru}^{9}$ decided to include the respiratory rate in a different manner (stratified by age) and, in addition, Argentina ${ }^{10}$ replaced the cyanosis assessment by the heart rate assessment.

More recently, Destino, et al. ${ }^{11}$ published a paper comparing the performance of the highly complex "Children's Hospital of Wisconsin score" with the highly simple modified respiratory distress assessment instrument (RDAI). It is not surprising that no differences were found between both instruments, especially given the evidence that indicates that chest retraction is the most valid indicator of an $\mathrm{O}_{2}$ saturation drop. ${ }^{12}$

Undoubtedly, the best tool to be used in standardized healthcare programs is the one that can be easily applied with objectivity and accuracy. The numerous attempts to do so that have been described in the literature show that this has not always been easy.

There is probably not one unique way to assess respiratory distress in infants, but the elements of the different scores (alone or in combination) can certainly help identify warning signs regarding a possible risk of cardiorespiratory dysfunction or death in this type of patients highly susceptible to hypoxemia.

Fernando Ferrero ${ }^{1}$ Laura Moreno ${ }^{2}$

${ }^{1}$ Hospital General de Niños Pedro de Elizalde, Buenos Aires.

${ }^{2}$ Clinical Pediatrics, School of Medicine, Universidad Nacional de Córdoba.

http://dx.doi.org/10.5546/aap.2013.189

1. World Health Organization: The world health report 2002 - Reducing Risks, Promoting Healthy Life. Geneva, 2002.

2. Silverman WA, Andersen DH. A controlled clinical trial of effects of water mist on obstructive respiratory signs, death rate and necropsy findings among premature infants. Pediatrics. 1956; 17(1):1-10.

3. Dabbous IA, TkachykJS,StammSJ.Adoubleblind study on the effects of corticosteroids in the treatment of bronchiolitis. Pediatrics. 1966; 37(3):477-84.

4. Pierson WE, Bierman CW, Kelley VC. A double-blind trial of corticosteroid therapy in status asthmaticus. Pediatrics. 1974; 54(3):282-8.

5. Tal A, Bavilski C, Yohai D, Bearman JE, Gorodischer R, MosesSW. Dexamethasone and salbutamol in the treatment of acute wheezing in infants. Pediatrics. 1983; 71(1):13-8.

6. Lowell DI, Lister G, Von Koss H, McCarthy P. Wheezing in infants: the response to epinephrine. Pediatrics. 1987; 79(6):939-45.

7. Meneghello J, Fanta E, Paris, E, Rosselot J. Pediatria, $4^{\circ}$ edicion, 1991(ed). Publicaciones Técnicas Mediterráneo, Chile. 1991.

8. Ministerio de Salud del Perú. Guía de práctica clínica síndrome de obstrucción bronquial en la niña y el niño. 2006.

9. Ministerio de Salud de Chile. Infección Respiratoria Baja de Manejo Ambulatorio en Menores de 5 años. 2012.

10. Ministerio de Salud de Argentina. Programa Nacional de infecciones respiratorias bajas. 2004.

11. Destino L, Weisgerber MC, Soung P, Bakalarski D, Yan R, Rehborg R, Wagner DR, Gorelick MH, Simpson P. Validity of Respiratory Scores in Bronchiolitis. Hospital Pediatrics 2012; 2(4):202-209.

12. Coarasa A, Giugno H,Cutri A, Loto Y, Torres F, Giubergia V, Ossorio MF, Durán P, González Pena H, FerreroF. Validación de una herramienta de predicción clínica simple para la evaluación de la gravedad en niños con síndrome bronquial obstructivo. Arch Argent Pediatr. 2010; 108(2):116-23. 